\title{
Article
}

\section{Hydrogen Infrastructure Project Risks in The Netherlands}

\author{
Pieter W. M. Vasbinder ${ }^{1}$, Antoine W. G. de Vries ${ }^{2}$ and Wim Westerman ${ }^{1, *(D)}$ \\ 1 Department of Economics, Econometrics and Finance, Faculty of Economics and Business, University of \\ Groningen, Nettelbosje 2, 9747 AE Groningen, The Netherlands; pietervasbinder@hotmail.com \\ 2 N.V. Nederlandse Gasunie, Concourslaan 17, 9727 KC Groningen, The Netherlands; \\ A.W.G.de.Vries@gasunie.nl \\ * Correspondence: w.westerman@rug.nl
}

\section{check for}

updates

Citation: Vasbinder, P.W.M.; de Vries, A.W.G.; Westerman, W. Hydrogen Infrastructure Project Risks in The Netherlands. Energies 2021, 14, 6009. https://doi.org/10.3390/en14196009

Academic Editor: Vincenzo Bianco

Received: 29 July 2021

Accepted: 16 September 2021

Published: 22 September 2021

Publisher's Note: MDPI stays neutral with regard to jurisdictional claims in published maps and institutional affiliations.

Copyright: (c) 2021 by the authors. Licensee MDPI, Basel, Switzerland. This article is an open access article distributed under the terms and conditions of the Creative Commons Attribution (CC BY) license (https:/ / creativecommons.org/licenses/by/ $4.0 /)$.

\begin{abstract}
This study aims to assess the potential risks of setting up a hydrogen infrastructure in the Netherlands. An integrated risk assessment framework, capable of analyzing projects, identifying risks and comparing projects, is used to identify and analyze the main risks in the upcoming Dutch hydrogen infrastructure project. A time multiplier is added to the framework to develop parameters. The impact of the different risk categories provided by the integrated framework is calculated using the discounted cash flow (DCF) model. Despite resource risks having the highest impact, scope risks are shown to be the most prominent in the hydrogen infrastructure project. To present the DCF model results, a risk assessment matrix is constructed. Compared to the conventional Risk Assessment Matrix (RAM) used to present project risks, this matrix presents additional information in terms of the internal rate of return and risk specifics.
\end{abstract}

Keywords: hydrogen infrastructure; risk identification; project comparison; discounted cash flow model; risk assessment matrix

\section{Introduction}

The European Commission aims to reduce net emissions of greenhouse gases in the European Union to zero by 2050. The Netherlands, among other countries, wants to use hydrogen as an energy source/carrier, in order to become carbon neutral. Many experts predict a flourishing future for the hydrogen gas economy, cf. Acar and Dincer [1]. Several Dutch industries already use hydrogen gas on a large scale as a resource, but hydrogen can also be employed to store and transport renewable energy to users, both industrial and private. In this way, hydrogen gas can replace oil, natural gas, coal and other polluting fossil energy sources. The focus in the Netherlands is on the production and storage of electricity through hydrogen gas. To make this happen, the Dutch Ministry of Economic Affairs and Climate paired up with several companies in the Netherlands to review the possibilities under the name of HyWay27. In doing so, the parties have been investigating the opportunities of a hydrogen infrastructure.

Research on hydrogen is rapidly developing. Studies are related to the risks and opportunities [2,3], demand and supply [4,5], the technology needed [6], hydrogen as a transportation fuel [7], the hydrogen supply chain [8] and the hydrogen economy, as well as the different types of hydrogen. Although research has been done on hydrogen application risks, this mostly relates to safety risks of infrastructures, instead of risks involved in setting up an infrastructure or a market.

An overview of relevant risks is created by comparing the unprecedented situation of developing a hydrogen infrastructure in the Netherlands with three other infrastructure projects lacking benchmarks at their time. A major tool used to analyze, identify and compare the four projects is the risk assessment framework of Shishodia et al. [9]. The impact of the risks is tested in a financial valuation model comparable to the discounted cash flow model presented by Koller et al. [10]. Using four different scenarios, the payoffs are 
measured in terms of the net present value and the internal rate of return of the project. However, to implement the risks in the discounted cash flow (DCF) model, they have to be converted to input parameters. A time multiplier is developed to take into account the project length. Once the impact of the risks is known, the risks are presented with the use of an overview technique. The technique used is the Risk Assessment Matrix (RAM). As with the discounted cash flow model, this technique is used by seminal companies that are involved in project risks to present the risks involved in a project. By analyzing how the RAM is used and implementing the research results in this matrix, the results from the present study are presented in a much detailed but comprehensible manner.

To get access to the necessary professional information, expert judgement and brainstorming techniques have been used. Throughout the entire research, exchange moments with experts on the field of hydrogen infrastructure, risk analysis, risk management, business case development, discounted cash flow modelling and other fields have taken place.

The core modelling was done in the course of the HyWay27 project. Based on the information provided by the parties involved in developing the project, the risk assessment framework by Shishodia [9] could be applied. Special attention was given to the calculation of the weighted average impact and the adjusted weighted average impact in weeks per subgroup of the risk categories. Twelve hydrogen transport projects were singled out. The changes in net present value with each risk category were determined, and the new internal rate of return for each risk category was calculated. The worst case was paid special attention. Furthermore, risk mitigation treatments could be suggested. The results provide insights in effect of risks on the value of the HyWay27 project. The modelling of the economic value is not the goal of this research, but is rather gaining comprehension of the impact of the risks involved.

Our study contributes to the academic literature and modelling practice in multiple ways. We may be the first to apply the risk assessment framework of Shishodia et al. [9] to the field of hydrogen infrastructure projects, which is highly complex and associated with a large number of risks. We add a time multiplier to this process, which takes the project length into account, develops input parameters for financial modelling purposes and combines this with the DCF framework of Koller et al. [10], in terms of internal returns. We visualize the outcomes in an augmented version of the traditional RAM matrix, which is better fitting for communication purposes. Finally, our study can help to identify, analyze and compare the risks as viewed by each of the stakeholders in hydrogen infrastructure projects.

In the next section, the literature on risk assessment techniques is examined. Section 3 presents an overview of the project characterization, the risk identification, the parameter development, the discounted cash flow modelling and the Risk Assessment Matrix. Section 4 is dedicated to assessing the Dutch hydrogen infrastructure project and benchmarking it with three other projects. Section 5 presents the findings from the sample project, the results from the discounted cash flow model and the constructed risk assessment matrix. Section 6 is devoted to conclusions that can be drawn and recommendations following from these.

\section{Risk Assessment Techniques}

As hydrogen is considered to be a relatively new energy source/carrier, it is extensively researched. Firstly, the literature on risk identification and analysis tools are discussed. Then, risk assessment within the hydrogen industry is looked at. Next, the conceptual framework of Shishodia et al. [9] is discussed. After the framework for identification and analysis is discussed, the development of the parameters is researched. Then the DCF model is discussed, which will be used to present the impact of the risks. Following this, research backing the RAM is reviewed, to further the understanding of how risks can be assessed. The RAM will be used to display the impacts of the risks of the hydrogen infrastructure. 
Ahmed et al. [11] provide an overview of base techniques for risk management in projects. Risk breakdown structures first focus on the risks that affect the entire project, and then investigate more specific risks with the use of the work breakdown structure. These have been used widely [12-16]. Another way of identifying risks is the usage of a risk profile. A risk profile is defined in this context as "a list of questions that address traditional areas of uncertainty on a project" [17]. Extensive research exists on the creation and usage of risk profiles [18-21]. However, there are also other tools for identifying risks within projects, such as checklists [22], influence diagrams [23], cause-and-effect diagrams [24] and more.

An issue with risk management and assessment techniques described above is that knowledge must be present to make a complete risk analysis. However, as to the hydrogen infrastructure, the obtainable knowledge is incomplete. To obtain the required knowledge, the integrated framework of Shishodia et al. [9] is used. To manage the risks involved in projects, Larson and Gray [17], state that it is important to first analyze them to identify the different sources of risk. By combining the research of Shenhar and Dvir [25] and Kendrick [26], the integrated framework can be used to first analyze a project and then identify its risks.

Markert et al. [27] and Kikukawa et al. [28] study the risk assessment and analysis of hydrogen fuelling stations; Hansen [29], Kasai et al. [30] and Kim et al. [31] assess the safety risks of a hydrogen infrastructure; Moonis et al. [32] discuss the commercial side of hydrogen as a fuel source; and Kim and Moon [33] publish on the strategic design of a hydrogen infrastructure. A major gap in the research on hydrogen as a fuel is a systematic evaluation method for determining risks in the development of a hydrogen infrastructure. This research wants to fill this gap by applying the integrated framework of Shishodia et al. [9] on the hydrogen infrastructure project.

To operationalize the risks in the integrated framework, parameters have to be developed with the use of firm specific information and expert opinions through brainstorming sessions. These parameters can then be plugged into a valuation model. Various valuation models exist for making decisions on whether to invest in a project. Within Gasunie, the Dutch state-owned natural gas distribution company that will be helping in the development and realization of the hydrogen infrastructure project, the discounted cash flow (DCF) model is used for the valuation of projects. It will be applied to evaluate the hydrogen infrastructure when the parameters are developed. Pathsetting McKinsey advisors state that the DCF model "discounts free cash flow at the weighted average cost of capital" [10] (p. 182).

The integrated framework is capable of analyzing projects, identifying risks and comparing projects; however, it lacks precision and easy to interpret information. Therefore, a RAM framework is added, to create a clear overview of the risks identified. As with the DCF model, Gasunie uses a RAM as its main tool for risk management. RAM frameworks are commonly used to identify and analyze risks, cf. articles by Hefaidh and Mébarek [34], Duan et al. [35] and Kikukawa et al. [28], as well as Kim and Moon [33]. All these contributions are related to the production, transportation or storage of hydrogen gas. In this research, the RAM will be used to create an overview of the risks identified by the integrated framework.

\section{Risk Assessment Frameworks}

Below, the integrated risk assessment framework of Shishodia et al. [9] will be explained first. This framework consists of two parts-project characterization and risk categories - which can be further delineated. Framework parameters are developed using expert insights. They are modelled financially by applying the discount cash flow (DCF) model. The RAM, as it is being used by practitioners, is discussed last.

\subsection{Integrated Risk Assessment Framework}

Shishodia et al. [9] developed a risk assessment framework consisting of the novelty, technology, complexity and pace (NTCP) framework designed by Shenhar and Dvir [25] 
and the risk categories scope, resource and schedule risks, as suggested by Kendrick [26]. The resulting integrated framework enables the comparison of different projects and identifies the trends and risks of the projects; its findings are also shown.

\subsubsection{Project Characterization}

The NTCP framework [25], also known as the Diamond Framework, deals with four characteristics that are deemed to be crucial for the identification of project risks and the selection of the appropriate project management approaches. Four characteristics are distinguished. Novelty is about the newness of the crucial aspects of the project. Firstly, a derivative product is a revised offering of a successful product. Secondly, platform novelty refers to a new version of an existing product. Thirdly, breakthrough products do not yet have a market that manufacturers can exploit. The higher the novelty score of the project, the higher the uncertainties associated with the market and technological requirements that are observed within the project. Technology refers to the level of technology involved in the project. Low-tech projects have almost no technological risks, whilst a super high-tech project is more vulnerable to risks regarding delays, cost overruns and product failure. Complexity is about how complicated the product, the process and thus the project is. The lowest degree of complexity is from 'assembly'. This form of complexity focuses on the materials, components, subsystems and the actual process. Secondly, 'system' provides information on how complicated manufacturing the product will be. Thirdly, 'array' refers to projects that are highly complicated, and consists of coordinating multiple systems. The pace is about the urgency of the project. A project with a regular pace has considerations that are more important than the time needed. Fast-competitive projects push the ideas to the market as fast as possible. Time-critical projects are those where missed deadlines and milestones can result in the failure of the entire project. Blitz projects are crisis projects with extremely urgent timing.

\subsubsection{Risk Categories}

Kendrick [26] identifies three risk categories and measures the frequency of risk occurrence and the degree of risk impacts over time. The first category, scope risk, is about the feasibility of the project, and refers to whether a project is achievable or lies beyond the capabilities of the people involved. Scope change risk has three subsections. Creep is regarded as the most dangerous type of change risk, and is referred to as uncontrolled changes and growth in the scope of the project at any point after the project assessment has taken place. A gap results from committing to a project without the necessities and requirements being arranged. Dependency emerges from external factors that affect the project. Scope defect risk refers to the breakdown of technology used in a project; it also has three sub-sections. Software risks are about the software being too difficult to handle, the capacity of the software being too low, or the risk that the software does not work in unexpected situations. Hardware risks relate to the hardware being too slow, requiring too much power or disrupting other electronic progress. Integration risks are about defects within the system of different subprojects that are dependent on each other.

Schedule risk is about the possibility of a project taking longer than originally planned. Schedule risks can be divided into three subsections. Estimate risks are about miscalculations in the expectations of deadlines within the project. They can refer to three different types. Learning curve risks are about a wrong estimation of the capabilities of technology and people. Deadline risks refer to unrealistic deadlines being imposed from outside the project, which are still retained instead of dropped or changed. Judgement risks are about the estimates being overoptimistic. Dependency risks are related to external factors that cause schedule slips; they can be divided into three different types. Legal risk is about the shift in legal and paperwork requirements of a project. Project interdependency risk refers to the situation where a project is dependent on the progress of another project. Infrastructure risk is about the interruption of technical services, such as computers, printers or networks used within a project. Delay risks are related to factors that cause schedule slips 
that are for certain degrees under the control of the project. They can be divided into four different types. Part risks refer to the uncertainty involved in the delivery and availability of parts that cause delay of the project. Information risk is about the unavailability of information to continue within the project. Hardware risks refer to the equipment needed and systems arriving late and thus causing a delay. Decision risks are about making of slow decisions and the timing of these decisions, which would cause a delay.

Resource risk is the chance of the project having a delay or even failure due to the lack of resources being available. The money risk is about the uncertainty of having limited funding, and thus causing a delay. It has only one type of risk, namely limitation, which is about the limitation of the funding that can cause a delay. The people risk refers to the people from within the project and the problems involving this group; it consists of four parts. Motivation risk is about the risk of people within the project losing motivation due to the lengthiness or difficulty of the project. Late start risk is the risk of starting the project at a later moment than planned due to the unavailability of people. Loss risk refers to the risk of permanent loss of people due to resignation, promotion to other positions, reassignment to other projects, health issues or other reasons for people to be permanently unavailable. Queuing risk is about the risk of getting delay due to the scarcity of people or technology. Outsourcing risk is about the people outside the project and the problems involving this group of people. It can be divided into two subsections. Late or poor output risks are about the risk of receiving late or poor products or services from parties outside the project, due to these parties being not closely involved in the development of the project. Delayed start risk is about having to start a new, complex relationship with the people from outside the project, and this can cause a delay.

\subsubsection{Integrated Framework Findings}

Shishodia et al. [9] research projects in three different industries, with one of these industries being engineering and construction. Three main groups of projects are found in the engineering and construction industry (see Table 1). Shishodia et al. [9] show that if the project is in Group 1, schedule risk is most prominent, with the other risks being non-present. When the project is best characterized as belonging to Group 2, resource risk is the prominent risk present, which will result in schedule risk. When the project is in Group 3, scope risk is the prominent risk present. It will bring about resource risk, which will then result in schedule risk. In sum, it can be said that the higher the group is, the more risks are present. Once all the data has been analyzed, the three reference projects can be assigned to the different groups. This will then help to get an idea about the most prominent risks present in the focal project, being the Dutch hydrogen infrastructure project. In doing so, it becomes clear on which risks should be focused when dealing with uncertainty surrounding this project.

Table 1. Project groups risks in the engineering and construction sector.

\begin{tabular}{cccc}
\hline E\&C Sector & Group 1 & Group 2 & Group 3 \\
\hline Novelty & Derivative & Derivative & Platform \\
\hline Technology & Low & Medium & Medium \\
\hline Complexity & Assembly & Array & Array \\
\hline Pace & Time-Critical & Regular & Regular \\
\hline Prominent Risk & Schedule & Resource & Scope \\
\hline
\end{tabular}

Source: [9].

\subsection{Parameter Development}

Application of the integrated framework, and specifically the risk categories of Kendrick [26], can provide users with the average impact in weeks. This impact can then, with the help of information provided by experts, be translated into financial values. Kendrick [26] uses the Project Experience Risk Information Library (PERIL) database to 
come up with the average impact of risks in weeks. Kendrick [26] calculated the average impact in weeks of each risk by adding all the delays and dividing it by the number of projects where the specific risk was the main cause of the delay. The average impact in weeks is an average of the cases where the risk is the main issue and therefore adding all the risks to see the impact on the hydrogen infrastructure would not make sense, since many of these do not cause material impacts.

The risk classification framework of Kendrick [26] is generic and not context-specific or sector-specific, which makes it fit to use for developing parameters. Kendrick [26] has defined three main groups of risks and eight subgroups of risks. These eight subgroups are formed based on the similarities the risks have within the group. This indirectly means there could be a correlation between the different risk types. To account for the possible correlation, a weighted average impact per subgroup is calculated. The weight assigned to the different risk types is based on the research of Kendrick [26]. The following procedure is applied.

1. Kendrick [26] provides the number of cases that a certain type of risk is the main cause of delay $\left(n^{R T}\right)$. This amount is divided by the total amount of projects that belong to the same subgroup $\left(N^{S G}\right)$. This results in a weight that can then be multiplied with the average impact of the type of risk $\left(w^{R T}\right)$.

- $\quad \frac{n^{R T}}{N^{S G}}=w^{R T}$

2. The weight of the type of risk is multiplied by the average impact in weeks of the type of risk $(A I)$, resulting in the weighted average impact in weeks for the type of risk $(w A I)$.

- $\quad w^{R T} * A I t^{R T}=w A I^{R T}$

3. The weighted average impact in weeks of different types of risk of the same subgroup is added to receive the average impact in weeks of the subgroup.

Before the average impact in weeks of the subgroup can be applied, a multiplier must be developed. Since Kendrick [26] reports the average impact in weeks based on a nine-month project, a correct multiplier must be developed to take into account projects that have a different time horizon. Hull [36] provides a solution here. He derives a T-day value-at-risk from a 1-day value-at-risk. By multiplying the 1-day value-at-risk with the square root of $T$, it is possible to get an approximation. This same method will be used in this research to receive an acceptable multiplier for different length projects. The 1-day value-at-risk can be substituted for the nine-month project as mentioned by Kendrick [26], and the T-day value-at-risk will be substituted for the project length of the project that is researched, which ultimately will be the hydrogen infrastructure project. After it is decided which inputs are actually affected by the presence of the risks, this study will take two steps to receive an approximation for the average impact in weeks for a $T$-year project:

1. The length of the hydrogen infrastructure project $\left(g t h^{H I}\right)$ in years will be divided by the length of a nine-month project $\left(\lg t h^{K}\right)$ in years. This provides a scale measure $(S M)$.

- $\frac{\lg t h^{H I}}{\lg t h^{K}}=S M$

2. The square root of the scale measure $(S M)$ will then be taken to provide a multiplier $(M)$. This multiple can then be used to provide approximations of the average impact in weeks for the $T$-year projects.

- $\sqrt{S M}=M$

\subsection{Discounted Cash Flow Modelling}

The parameters resulting from the identified risks are put into a discounted cash flow (DCF) model. With the use of this DCF model, the net present value (NPV) can be calculated. To arrive at the NPV of the project, first the free cash flows (FCF) from construction start to operation end have to be calculated. This is done by singling out the transport tariff, 
revenues, operating expenditures, depreciation, tax and capital expenditures. The values of these different inputs are generated by using the information provided by the HyWay 27 project. Transport tariff and revenue will have a positive influence on the FCF, whereas operating expenditures, depreciation, tax and capital expenditures will have a negative influence. By adding up these values, the FCF of a given year is calculated. The resulting FCF is then discounted against the weighted cost of capital (WACC). The discounted cash flows for each year are then added up, which results in the NPV of the project.

The way the parameters are tested is through multiple scenarios. In these scenarios, being used as base cases, the three different risk categories as mentioned in Section 3.1.2 are independently implemented through the parameters developed before and all the risk categories are implemented at the same time. This way, four scenarios are developed:

1. the scope scenario, where all scope risks take place, ceteris paribus.

2. the schedule scenario, where all schedule risks take place, ceteris paribus.

3. the resource scenario, where all resource risks take place, ceteris paribus.

4. the worst-case scenario, where all risks take place, ceteris paribus.

With these four scenarios and the input of the final report of HyWay27 [37] about the parameters, it is possible to determine which risks have the most impact.

\subsection{Risk Assessment Matrix}

The construction of a RAM can be divided into four different phases. The first phase is the determination of the risk appetite for the internal environment. Here the risk appetite of the participating company is assessed. The second phase refers to appointing the participants of the risk assessment. Risk assessment should be done with multiple people from the different parties involved in the project. The third phase is the execution of the risk assessment. Within this phase, there are four steps: determining the scope of the risk assessment, identification of the risks and threats, inventorying and establishing the control measures and finally the establishment and evaluation of the residual risks. In phase four, the specific risks are reported. These phases are a continuous process and the order can be changed. For this research, phase 1, phase 2 and phase 3 are already done with the integrated framework of Shishodia et al. [9] and the DCF-model. Therefore, only phase 4 applies here.

The report of the RAM consists out of two axes, probability on the horizontal axis and impact on the vertical axis. Both these axes have a scale of 1 to 5 , with 1 being low impact and probability and 5 being high impact and probability. Each risk will receive a number to be easily identified by the interpreter. The risks are then inserted in the matrix based on the results from the integrated framework, which then results in an overview of the different risks. The impact of the risk on the project can be related to four different impact measures. The financial impact is displayed in euros as a percentage of the total project budget without changes or contingency. The planning impact is displayed in days/weeks/months as a percentage of the total planning. The scope impact is displayed in either reduction or extension of the project. The compliance impact is displayed in form of shifts in regulations, laws, standards or guidelines.

When presenting the developed RAM, two matrixes are used to depict risks in a project. The first matrix is the pre-mitigation heat map and the second matrix is the postmitigation heat map. Mitigation refers to the dealing of risks. In these two matrixes, the same risks are depicted, but due to mitigation, their positions on the matrix may have changed. Furthermore, a distinction is made between different risks based on the phase of the project. These three phases refer to the pre-final investment decision, the period between the final investment decision and the delivery and the operational period. However, pre-final investment decision risks will disappear when the final investment decision is made. Only the pre-mitigation RAM is built to the hydrogen infrastructure project, as the post-mitigation RAM cannot be constructed yet. 


\section{The Dutch Hydrogen Infrastructure Project}

In this section, the hydrogen infrastructure project is reviewed, based on research articles and expert insights. First, the sources of information about the risks involved in the individual projects will be introduced. Secondly, the project at hand will be shortly presented. Thirdly, the integrated framework of Shishodia et al. [9] will be applied, and a case description is created. Lastly, the sample project is briefly benchmarked with three comparable infrastructure projects.

\subsection{Sources of Information}

Information about the hydrogen infrastructure project is gathered from various sources. For the general information about the risks involved in setting up a hydrogen infrastructure, professional literature from multiple fields of expertise are used. Since existing literature on setting up a hydrogen infrastructure is limited, literature on similar projects is used to fill in gaps. For more in-depth information about the risks of the project, expert insight has been provided by Gasunie. At times, other experts have been consulted. HyWay27 is the name of the study about the use of infrastructure for the transport and storage of hydrogen in the Netherlands, undertaken by Gasunie, TenneT and the Ministry of Economic Affairs. The goal of the resulting project is to establish a sustainable hydrogen infrastructure. Its final report [37] describes the possibilities of such an infrastructure.

\subsection{Project Presentation}

The entire HyWay27 project consists out of twelve small separate projects of three years each. The sub-projects will start at different times between 2021 until 2026 and are to be completed in 2030 at the latest. The project aims to reuse existing gas pipelines and refit these pipelines so that hydrogen can be transported through them. In some cases, new pipelines have to be built to connect (potential) suppliers and customers. Important to note is that Gasunie will be executing the project when it comes to the reuse and refit of existing gas pipelines and the construction of new pipelines.

Gasunie is experienced in the development of infrastructures for energy transportation, but there is no hydrogen market in the Netherlands so far. This is considered to be the biggest risk of the project by Gasunie, as it makes or breaks the project. At the time of writing, both the suppliers and the buyers of hydrogen as a fuel are uncertain about the future of hydrogen and thus unwilling to make investments to build up a market. For Gasunie to be standing between these two groups with uncertainty is a difficult spot to be in, concerning the project. Therefore, it can be argued that the hydrogen infrastructure project can best be defined as a "breakthrough" project for Gasunie.

The risks involved in being a breakthrough project is that there is no existing market and that little knowledge exists on the topic of the project. The risks associated with the situation are scope creep and scope gap. Scope creep has a low probability and impact, as the project is focused only on the infrastructure surrounding hydrogen. Scope gap has a low probability, however high impact. Because the project enters new territory, changes in the scope will result in costs and time wasted as new information must be gathered.

The degree of technical difficulty is "high", as the technology used to transport hydrogen is underdeveloped. This means that new and better technologies must be developed, resulting in a lot of risks with regards to the technology used in the infrastructure. The main issue with the production of hydrogen is that currently, a lot of energy is lost in the process. This issue has to be fixed before hydrogen can make a significant change in the green energy market. Thus, the risks of hardware and software defects have a high impact and high probability.

The project involves the development of new technologies and multiple stakeholders working together, so the complexity of the project can be defined as an 'array'. The stakeholders range all over the spectrum of demand and supply. Because there is no existing market, both suppliers and customers are unknown. A high occurrence of schedule estimate risks can be anticipated, due to wrongly set deadlines. Since the project involves 
new technologies and information, there is a high possibility that complicated decisions must be made. Because the project involves multiple stakeholders, the probability for delay risk of information can be classified as high, while the impact can be classified as low.

With Gasunie being a state-owned company, the probability of the money risk is low, but the impact of this risk is regarded as very high. As with the resource risk of people, the probability will be medium, but the impact will be high. Gasunie is known for planning and making sure that the required resources are always at its disposal, but if this is not the case, this could lead to serious delays or costs. It is important to notice that many different infrastructure projects are planned in the Netherlands and elsewhere in Europe. This means that there is a high probability of outsourcing risks, both relating to late/poor output and delayed start, as contractors can be overwhelmed by the amounts of requests they are getting.

The reason for the construction of the hydrogen infrastructure is the Dutch government's demand for green energy; the planned pace of the project can be interpreted in terms of 'the sooner, the better', and can be characterized as 'regular'. The risks due to legal dependencies have a lower probability and impact. The construction of the entire hydrogen infrastructure has a duration of six years; construction will start in 2024 and the deadline is imposed in 2030.

\subsection{Project Benchmarking}

The Dutch hydrogen infrastructure project has been benchmarked with three comparable infrastructure projects, which are described below.

The Channel Tunnel is a three-tunnel construction project between France and England, undertaken by Eurotunnel, consisting of Channel Tunnel Group (U.K.) and France Manche S.A. (France). Construction started in 1988, and was finished in 1994. In 2004, the total costs of the construction of the Channel Tunnel and all equipment needed added up to 4650 million GBP. Public information is available [38-42].

TenneT is a seasoned, full-around, European electricity transmission system operator. TenneT is under the obligation to connect wind farms in the North Sea to the German power grid. The goal was to connect a capacity of 20 gigawatts to the power grid by 2030 . Public information about the TenneT grid connection projects has been obtained through various sources [43-47].

Bacton Balgzand Line (BBL) is a gas pipeline $(235 \mathrm{~km})$ between Balgzand (the Netherlands) and Bacton (United Kingdom). The project was undertaken by Gasunie (the Netherlands), E.ON (Germany) and Fluxys (Belgium) from 2004 until 2006. The costs of the construction of the gas pipeline were estimated to be around 500 million euros. Public information about the Bacton Balgzand Line (BBL) can e.g., be retrieved from [47-49].

Table 2 would suggest that the hydrogen infrastructure project is mostly in line with the TenneT connection. Therefore, the focus should be on the scope risks within the hydrogen infrastructure project. It is important to remember that all of the other risks are still present, and therefore important to investigate. It can be concluded that the hydrogen infrastructure is technically complex, and involves the highest number of risks, according to the comparison with the Channel Tunnel project, the TenneT connection project and the Bacton Balgzand Line project. 
Table 2. Overview of the four projects examined in this research.

\begin{tabular}{ccccc}
\hline & Channel Tunnel & TenneT Connection & BBL & Hydrogen Infra. \\
\hline Novelty & Derivative & Breakthrough & Derivative & Breakthrough \\
\hline Technology & High & Super-high & Medium & High \\
\hline Complexity & Array & System & Array & Array \\
\hline Pace & Regular & Regular & Regular & Regular \\
\hline Corresponding group & Group 2 & Group 3 & Group 2 & Group 3 \\
\hline Prominent Risk & Resource & Scope & Resource & Scope \\
\hline
\end{tabular}

\section{Hydrogen Infrastructure Project Review}

In this section, the parameter development and the discounted cash flow modelling will be reviewed for the hydrogen infrastructure project. After this, the resulting risk assessment matrix is built based on these results, as well as input from experts in the natural gas infrastructure field and beyond.

\subsection{Parameter Development}

After the integrated framework has been applied, the weighted average impact of the different risk subgroups can be calculated. As can be read in the case description above, the separate subprojects will be estimated to each have a length of three years. This means that the multiplier that will be used to get the right impact of the different risks will be equal to:

1. $\frac{L G T H^{H I}}{L G T H^{K}}=S M \rightarrow \frac{3}{0,75}=4$

2. $\sqrt{S M}=M \rightarrow \sqrt{4}=2$

The multiplier is then combined with the weighted average impact in weeks to obtain the adjusted weighted impact in weeks. Table 3 provides an overview of the eight different subgroups, the weighted average impact in weeks and the adjusted weighted impact in weeks.

Table 3. The weighted average impact and the adjusted weighted average impact in weeks per subgroup of the risk categories.

\begin{tabular}{ccc}
\hline & Weighted Average Impact in Weeks & Adjusted Weighted Impact in Weeks \\
\hline Scope: Changes & 8.26 & 16.52 \\
\hline Scope: Defects & 7.05 & 14.11 \\
\hline Schedule: Estimates & 7.56 & 15.13 \\
\hline Schedule: Dependency & 6.40 & 12.80 \\
\hline Schedule: Delay & 5.02 & 10.04 \\
\hline Resource: Money & 13.40 & 26.80 \\
\hline Resource: People & 5.73 & 11.47 \\
\hline Resource: Outsourcing & 6.69 & 13.37 \\
\hline
\end{tabular}

When adjusting parameters for risks, three different groups can be dealt with: the capital expenditures (CAPEX), the schedule of construction and thus the start of operations, as well as the revenues. When it is possible to adjust these without consequences, this should be done. If the project does not allow for unsanctioned changes in this respect, the CAPEX is preferred to be changed over the revenue. Participants of various brainstorm sessions hold that the parameter used for the risks depends on the stage the project is in. There are two major stages in a project. The first decision stage (pre-final investment) allows for better changes without sanctions, while after the second decision stage (final investment), major commitments are set and thus changes can be made less easily. Another 
difference between the two stages can be found in the types of risk involved, as some risks tend to only appear in either one of the stages, instead of both.

Based on the above, several assumptions have to be made to be able to insert parameters for the risks into the discounted cash flow model. Firstly, the deadline of the project is confirmed and cannot be changed; the result of this is that the CAPEX components will be adjusted for the presence of risks. Secondly, the stage of the project is not taken into account. Because all types of risks are being looked at, the project is being looked at jointly in both the pre-final investment decision stage and the post-final investment decision stage.

The CAPEX used in the discounted cash flow model is divided into two components: fixed expenditures and variable expenditures. The fixed expenditures consist out of the (pre-agreed) costs of the pipe segments for a new pipeline. Pipe materials prices are assumed not to change over time. The variable expenditures consist of the refit costs for the existing gas pipelines into hydrogen pipelines, construction of new hydrogen pipelines, replacement costs of valves and other costs. These three components are referred to as the new construction costs of the hydrogen pipeline. The variable expenditures are then divided by 156.532 weeks to get the weekly variable expenditures (in EUR million), since an individual project has a three-year time horizon. The weekly variable expenditure is then multiplied with the weighted adjusted impact in weeks, in order to obtain the impact of the existence of a risk subgroup on a project (in EUR million).

\subsection{Discounted Cash Flow Modelling}

To receive the needed results, the following discounted cash flow modelling assumptions are made. A neutral value base case for each of the twelve different projects, a net present value (NPV) of zero is created by adjusting the transport to realize a break-even value for the NPV. This value for the tariff is then inserted in the model as the starting tariff. This is done to easily interpret the results of the changing CAPEX. Next to this, the weighted average cost of capital (WACC) will not change due to the presence of extraordinary risks. Normally, due to the presence of such risks, the weighted average cost of capital would have changed. As discussed before, however, the model used is basic, and therefore the WACC remains fixed. With these assumptions in mind, expected changes in the NPV can be observed, and the effects of the risk subgroups will become visible. As mentioned in the assumptions above, the NPV is equal to zero in each one of the twelve subprojects. Because the risk assessment matrix is based on the internal rate of return measure (to be discussed later), the new internal rate of return is also displayed. The internal rate of return in the base case is equal to $6 \%$ in each one of the twelve projects, which is equal to the weighted average cost of capital. The worst case refers to the scenario where all the risks that are referred to in the framework will happen. In this case, which is presumed to be logical, the change in net present value and the internal rate of return for each of the different subprojects will be the lowest. Refer also to Table 4 .

As mentioned before, the twelve different projects will not take place at the same, but partially consecutively. Therefore, to calculate the total impact of the risks on the entire hydrogen infrastructure, a learning effect is implemented. Gasunie, together with the other companies involved in HyWay27, are experienced in the construction and development of the pipelines; therefore, not all twelve projects need to be used in the calculations. Two projects start in 2021, which will be the first projects to be executed. These are Rib No-NL and Rib Rotterdam. Only these projects are considered when calculating the impact of the risks on the entire hydrogen infrastructure. It is thus assumed that learning effects materialize only here. To determine the weight of the individual projects, the capital expenditures of the two projects in the base case are added, and the portion of each project is calculated as a percentage. These percentages are then multiplied with the corresponding net present value and the internal rate of return before the total impact is calculated. The results represent the total change in net present value and the new internal rate of return of the entire hydrogen infrastructure. Refer to Table 5. 
Table 4. The changes in net present value with each risk category and worst case for the twelve hydrogen projects, as well as the new internal rate of return for each risk category and the worst case for the twelve hydrogen projects.

\begin{tabular}{|c|c|c|c|c|c|c|c|c|}
\hline & \multicolumn{2}{|c|}{ Scope Risks } & \multicolumn{2}{|c|}{ Schedule Risks } & \multicolumn{2}{|c|}{ Resource Risks } & \multicolumn{2}{|c|}{ Worst Case } \\
\hline & $\begin{array}{l}\text { Change in } \\
\text { Net Present } \\
\text { Value (m€) }\end{array}$ & $\begin{array}{c}\text { Internal } \\
\text { Rate of } \\
\text { Return }\end{array}$ & $\begin{array}{l}\text { Change in } \\
\text { Net Present } \\
\text { Value (m€) }\end{array}$ & $\begin{array}{c}\text { Internal } \\
\text { Rate of } \\
\text { Return }\end{array}$ & $\begin{array}{l}\text { Change in } \\
\text { Net Present } \\
\text { Value (m€) }\end{array}$ & $\begin{array}{l}\text { Internal } \\
\text { Rate of } \\
\text { Return }\end{array}$ & $\begin{array}{l}\text { Change in } \\
\text { Net Present } \\
\text { Value (m€) }\end{array}$ & $\begin{array}{c}\text { Internal } \\
\text { Rate of } \\
\text { Return }\end{array}$ \\
\hline Rib No-NL & -22 & $5.3 \%$ & -27 & $5.1 \%$ & -37 & $4.8 \%$ & -86 & $3.6 \%$ \\
\hline $\begin{array}{c}\text { Rib } \\
\text { Rotterdam }\end{array}$ & -48 & $5.0 \%$ & -60 & $4.8 \%$ & -81 & $4.4 \%$ & -189 & $3.0 \%$ \\
\hline $\begin{array}{c}\text { Rib } \\
\text { Amsterdam }\end{array}$ & -11 & $5.1 \%$ & -13 & $4.9 \%$ & -18 & $4.5 \%$ & -42 & $3.2 \%$ \\
\hline Rib Zeeland & -17 & $5.0 \%$ & -21 & $4.8 \%$ & -28 & $4.4 \%$ & -66 & $2.9 \%$ \\
\hline $\begin{array}{l}\text { NO-NL- } \\
\text { IJmond }\end{array}$ & -16 & $5.6 \%$ & -40 & $5.1 \%$ & -55 & $4.8 \%$ & -107 & $4.0 \%$ \\
\hline $\begin{array}{l}\text { IJmond- } \\
\text { Rijnmond }\end{array}$ & -8 & $5.5 \%$ & -10 & $5.4 \%$ & -14 & $5.2 \%$ & -32 & $4.3 \%$ \\
\hline $\begin{array}{l}\text { Rijnmond- } \\
\text { Zeeland }\end{array}$ & -3 & $5.7 \%$ & -7 & $5.4 \%$ & -9 & $5.2 \%$ & -22 & $4.3 \%$ \\
\hline $\begin{array}{l}\text { Elim- } \\
\text { Limburg }\end{array}$ & -22 & $5.4 \%$ & -27 & $5.2 \%$ & -37 & $5.0 \%$ & -85 & $3.9 \%$ \\
\hline $\begin{array}{l}\text { Ravenstein- } \\
\text { Ossendrecht }\end{array}$ & -8 & $5.5 \%$ & -10 & $5.3 \%$ & -13 & $5.1 \%$ & -31 & $4.1 \%$ \\
\hline $\begin{array}{l}\text { Export Oude } \\
\text { Statenzijl } \\
\text { Export }\end{array}$ & -2 & $5.5 \%$ & -2 & $5.4 \%$ & -3 & $5.1 \%$ & -7 & $4.2 \%$ \\
\hline $\begin{array}{l}\text { Winter- } \\
\text { swijk/Zevenaar }\end{array}$ & -9 & $5.5 \%$ & -12 & $5.4 \%$ & -16 & $5.2 \%$ & -37 & $4.2 \%$ \\
\hline $\begin{array}{l}\text { Export Hil- } \\
\text { varenbeek }\end{array}$ & -1 & $5.3 \%$ & -1 & $5.1 \%$ & -2 & $4.9 \%$ & -5 & $3.7 \%$ \\
\hline
\end{tabular}

Table 5. The change in net present value for each risk category and worst case for the entire hydrogen infrastructure, the new internal rate of return for each risk category and the worst case.

\begin{tabular}{ccc}
\hline & Change in Net Present Value $(\mathbf{\in} \mathbf{m})$ & Change in Internal Rate of Return \\
\hline Scope Risks & -38.0 & $0.91 \%$ \\
\hline Schedule Risks & -47.1 & $1.10 \%$ \\
\hline Resource Risks & -64.0 & $1.43 \%$ \\
\hline Worst Case & -149.0 & $2.78 \%$ \\
\hline
\end{tabular}

\subsection{Risk Assessment Matrix}

For the construction of the RAM input from experts from the field have been acquired. Based on the discussion with these experts, the following findings are implemented in the RAM of the entire hydrogen infrastructure.

Within the RAM, four different impact measures are used: financial impact, planning impact, scope impact and compliance impact. These impact measures are found to be insufficient in presenting the risks, however, as the four measures make it difficult to compare different risks mutually. Therefore, it was opted to use a different measure to represent the impact: the internal rate of return (IRR), which is the discount rate that equalizes the net present value of a project to zero. The IRR is a good measure for assessing the impact of risks, as it makes them mutually comparable. In the RAM of the hydrogen infrastructure, a 5-point scale is used to classify an IRR impact as insignificant (when changing $<0.01 \%$ ), minor (when changing $>0.01-<0.05 \%$ ), moderate (when changing $>0.05-<0.25 \%$ ), significant (when changing $>0.25-<1.00 \%$ ) or jeopardizing (when changing $>1.00 \%$ ). The scale is based on the insights of various experts, but might be subject to changes in the future. The 
internal rate of return will be displayed on the vertical axis, while the probability will be displayed on the horizontal axis.

\subsubsection{Treatment of Risks}

Another point of interest with regards to the input from the experts is the amount of information. As mentioned before, companies use both pre- and post-mitigation matrices. In these matrixes, the risks change positions on the matrix, due to the treatment that the risks have been given. Some information is missing, however: the type of treatment the risks have received during the mitigation. It is important to add this, as it provides information about the way the risks are dealt with. To insert this information, the types of treatment must be identified. According to the experts, there are four different ways of dealing with risks, called the four Ts of risk management.

The first $\mathrm{T}$ stands for terminate, which is the avoidance or elimination of a certain risk. This treatment is used for risks with high impacts, where the probability is unlikely to decrease in the future, and the risks are difficult to influence. An example of terminating a risk is deciding not to continue or even begin a project. The second $\mathrm{T}$ stands for treat, and refers to the control or reduction of a certain risk. This treatment is mostly used for risks that have a small impact and that are influenceable. The most important issue, in this case, is performing a cost-benefit analysis. If the benefits exceed the costs of treating the risk, the company should try to treat the risk. An example of a treat mitigation is the testing of gas pipelines before using them, in order to reduce the likelihood of defects or leaks when in use. The third $\mathrm{T}$ stands for transfer, which is shifting a certain risk to a third party either by insurance or contractually. The risks that are transferred have a low real probability but a high impact. When transferring the risk to a third party, compensation from the third party is acquired when the risk occurs. Important to note in case the risk is transferred is that risk being transferred must be related to the third party, and be reasonable. An example of transferring a risk is buying an insurance that covers parts of construction risk, e.g., with horizontal drilling. The fourth $\mathrm{T}$ refers to tolerate, which is the acceptation or retainment of a certain risk. This treatment is similar to the treat treatment, but the costs exceed the benefits. The company may only be able to tolerate the risk, as the other treatments will not be applicable. Tolerating does not mean that the company stops looking at the risk; it rather means that it takes measures when the risk does appear. Risks can be tolerated by identifying, understanding, acknowledging and developing a plan of dealing with each of the risks that are tolerated. Important to note is that each of the four mitigation treatments will cost money, either directly or indirectly, since it only rarely occurs that a mitigation treatment chosen will be free of costs. The costs of the mitigation treatments therefore have to be taken into account when choosing the most fitting treatment of a certain risk.

The four treatments can be depicted in the matrix by giving the numbers that represent the risks a different color for each of the different ways of treating them. The numbers representing the different risks will have the following colors: red (terminate), yellow (treat), blue (transfer) and green (tolerate). This way of coloring the numbers representing the risks is added to the RAM of the hydrogen infrastructure.

\subsubsection{Results}

To demonstrate the way the RAM developed for the hydrogen infrastructure works, the entire hydrogen infrastructure as calculated with learning effects will be used. However, only the risks concerned with the hydrogen economy are displayed, as those risks influence the hydrogen infrastructure. These risks will provide an internal rate of return, with which the appropriate mitigation treatment can be determined and the appropriate RAM can be developed.

The companies involved have experience in the construction of pipelines and therefore some of the risks will not be taken into account, as experience in building infrastructure will make these risks not worth mentioning. Here a difference will be made between risks that are concerned with the hydrogen economy and risks that are concerned with the 
construction of new infrastructure. Risks that are concerned with the hydrogen economy will be new risks for the companies involved, as excessive research on hydrogen still must be done. This means that the assumption is made that the learning effect results in the application of only certain risks.

To determine the risks concerned with the hydrogen economy, the risk categories of Kendrick [26] are used. For each of the different risks, it has been determined whether the risk is related to the hydrogen economy, which has resulted in the eight risk categories referred to earlier. For each of these risks, it is determined whether the risks are to happen before or after the final investment decision (FID). This is done by either making the cells representing the risks in the RAM white (pre-FID) or blue (post-FID). When it is determined whether the risk should be incorporated in the RAM, the mitigation treatments have to be determined. As stated before, there are four different treatments: terminate, treat, transfer and tolerate. The treatments and argumentation for these treatments for each of the eight risk categories can be found in Table 6 .

Table 6. The change in the internal rate of return, the mitigation treatments and argumentations for the hydrogen economy risks.

\begin{tabular}{llll}
\hline $\begin{array}{l}\text { Hydrogen Economy } \\
\text { Risks }\end{array}$ & $\begin{array}{l}\text { Change in } \\
\text { Internal Rate } \\
\text { of Return }\end{array}$ & $\begin{array}{l}\text { Mitigation } \\
\text { Treatment }\end{array}$ & Argumentation \\
\hline
\end{tabular}

Software defects will result in changes in the hydrogen project scope. Normally, it is chosen to terminate risks that will cause

(1) Defects: Software $-0.46 \%$ Terminate scope changes. Such changes will have too much impact on the project, not only when related to costs but also the entire idea of the project. Therefore, the software risk should be terminated, as it is considered having too much impact and the probability of the risk is not expected to decrease when treated, transferred or tolerated.

As with defects in software, hardware defects can also result in changes in the scope of the hydrogen project. Therefore, these

(2) Defects: Hardware $-0.43 \%$

Terminate risks will also be terminated. The risk is considered having too much impact and the probability of the risk is not expected to decrease.

The hydrogen project is initiated by state-owned companies and the government as part of the project. The risks of dependency on legal changes should be transferred to the party that has the most (3) Dependency: Legal $-0.47 \%$ Transfer influence on this risk, which is the government. With this is meant that when there will be changes in legislation, regulations or permits, the government should be held accountable for increasing costs in the project.

Because multiple parties are involved in the hydrogen project, information should be easily available for each party. When all parties have to wait for information, the costs of delay are

(4) Delay: Information

Treat expected to increase. Therefore, the risks of delay due to missing information should be treated. It is expected that the costs of developing a platform where all information is stored will be cheaper than tolerating the delays due to missing information.

In the multi-party hydrogen project set up, decisions must be made from different perspectives. This can cause delays, as different perspectives can cause disagreements. However, due to

(5) Delay:

Decision
$-0.20 \%$

Treat the experience of the parties involved, this risk can be tolerated, as the impact is considered to be moderate. The parties involved in the project can tolerate the risk of delays due to indecisiveness, but should closely monitor the moments where decisions have to be made.

\begin{tabular}{|c|c|c|c|}
\hline $\begin{array}{l}\text { (6) People: } \\
\text { Loss }\end{array}$ & $-0.43 \%$ & Treat & $\begin{array}{l}\text { The replacement of personnel is considered to be cheap and easy. } \\
\text { Therefore, it is chosen to treat this risk. }\end{array}$ \\
\hline
\end{tabular}


Table 6. Cont.

The outsourcing is in the case of the hydrogen infrastructure via

(7) Outsourcing:

Late or Poor Output
$-0.47 \% \quad$ Transfer

(8) Outsourcing:

Delayed Start
$-0.28 \% \quad$ Transfer contractors. These contractors are expected to be occupied with projects, therefore the risk of late or poor output is present. This risk depends on the ability of the contractors. Therefore, if the contractors cannot deliver, they should be made responsible.

As with the late or poor output of the contractors, the responsibility of a delayed start is with the contractors. Therefore, this risk should be transferred to the appropriate party.

Table 6, combined with the information from the data section on the hydrogen infrastructure, provides the information needed to fill in the RAM of the hydrogen infrastructure. This results in Figure 1, which displays the pre-mitigation RAM of the hydrogen infrastructure. In the RAM, the new impact measure of the internal rate of return is implemented on the vertical axis. On the horizontal axis, the probability is displayed. The cells with the numbers now provide two forms of information. The color of the cell itself represents whether the risk occurs pre-FID (white) or post-FID (blue). The color for the number representing the different risks now display the mitigation treatment that will be used. Red numbers mean that the risk should be terminated (1\&2), yellow numbers mean that the risk should be treated $(4,5 \& 6)$ and blue numbers mean that the risk should be transferred $(3,7 \& 8)$, and as can be seen in Table 6 , there are no risks present that have been assigned the tolerate treatment (green).

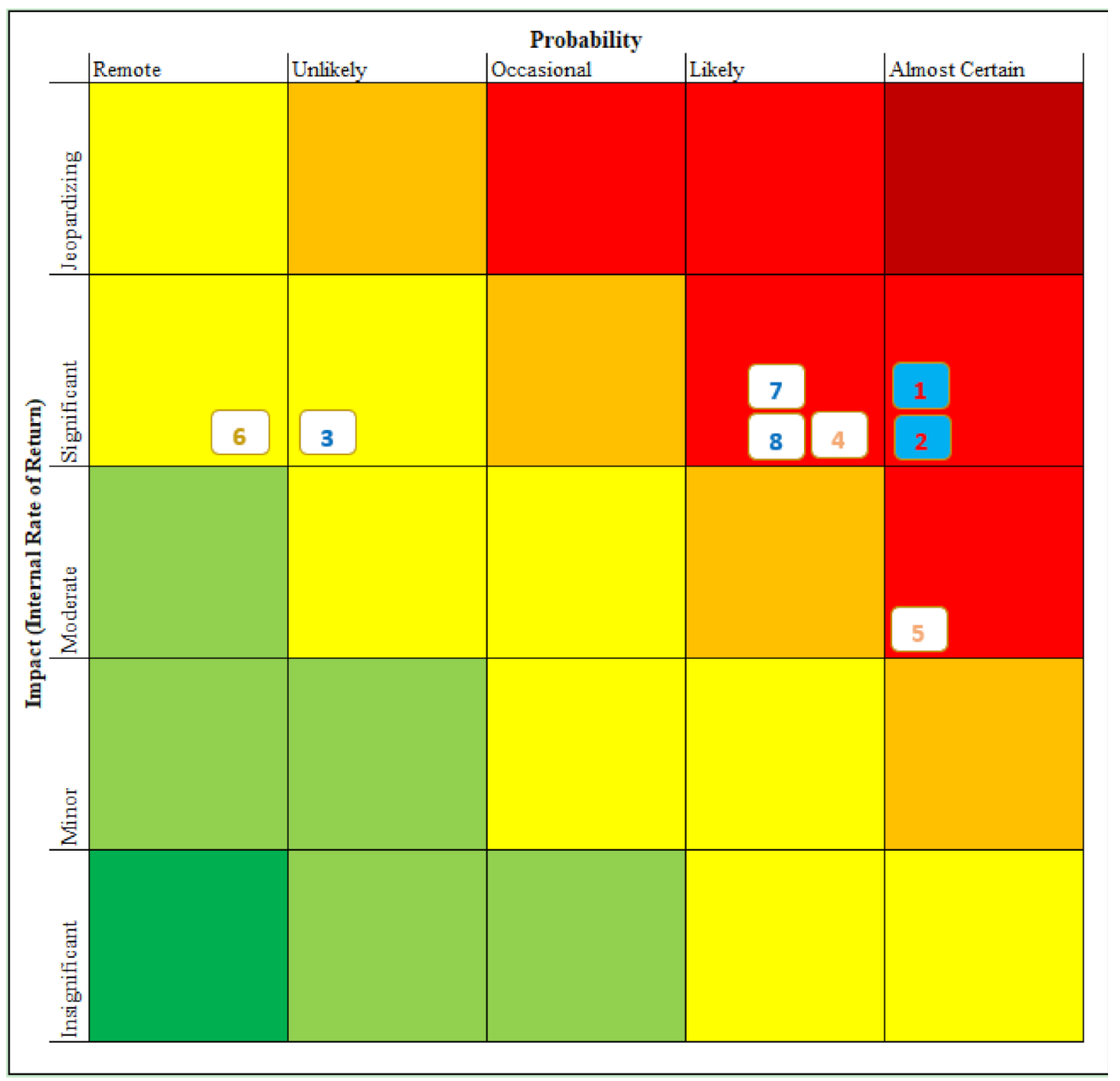

Figure 1. The pre-mitigation risk assessment matrix of the hydrogen infrastructure project. 


\section{Conclusions and Recommendations}

Project comparison can be used to anticipate potential risks in projects. The integrated framework is a tool that can predict which risks are the most prominent in a project. When applying it, the most prominent risk of the hydrogen infrastructure is determined as being scope risk. The Dutch hydrogen infrastructure project studied here can be classified as a breakthrough project with high technological difficulty, array complexity and a regular pace. Projects with these characteristics have scope risks as the main risk. The hydrogen infrastructure can therefore best be described as a highly complex project with a large number of risks involved.

To calculate the impact of the risks of a project, a multiplier has been developed, which takes the length of the project into account. Together with the findings of the risk categories, the impact in weeks of the risks on the project in question can be calculated. The resulting impact in weeks can then be transferred to the discounted cash flow model. The discounted cash flow model can measure the payoffs of the risks in term of the net present value or the internal rate of return of the project. For the hydrogen infrastructure, a base case is drawn from the final HyWay 27 report [37]. To implement the risks in the discounted cash flow model, expert inputs are used. Capital expenditures are adjusted to account for the presence of the risks. Not all of the risks from the integrated framework influence the project materially, and experience allows for not using all of the twelve different subprojects when calculating the impact of the risks. The impact of the resource risks is high, but scope risks matter the most.

The results of the discounted cash flow model are used to construct a risk assessment matrix of the hydrogen infrastructure. Several adjustments are made as compared to the conventionally used matrix. The first adjustment is the use of the internal rate of return to measure the impact of risks. The second adjustment is the addition of colors to the numbers representing the risks in the matrix. Each color represents one of the four mitigation treatments. Furthermore, a distinction is made between risks that are related to the hydrogen economy and the risks that are related to the construction of new infrastructure. Expert information has helped to improve the matrix.

The project environment of the hydrogen infrastructure as initiated by the HyWay27 partners can best be described as uncertain, innovative and time pressured. It shows that our study has not uncovered major ex ante risks, and expected economic losses that could cause the project as a whole to be terminated, treated or transferred. Nevertheless, the study provides insights in which risks have the highest impact on the HyWay27 as it stands for today. By researching the possibilities of mitigating risks, the impact will also decrease accordingly. Here, the DCF-based considerations can be made on whether or not to terminate, treat or transfer the risks.

Based on the dialogues with experts for this study, a suggestion is to make (potential) suppliers and customers aware of the time pressure that surrounds the energy transition in the Netherlands. This study can help to identify, analyze and compare all the risks seen by each of the stakeholders in the hydrogen economy. The participants can perform their research based on the methods described here.

Having said this, our delineation of risks may not directly refer to the most important risks a project may encounter. For example, safety risk is often accepted to be a major risk category. It can seriously affect the project risk and is to be assessed seriously wherever needed. Moreover, individual risks may be intertwined and hard to separate. As an example, complexity and pace issues may raise safety risk, novelty may increase safety risk and a technologically difficult project may introduce new safety risk. In reverse, it may also be true that safety risk negatively affects resource risk and schedule risk. In our approach, expert opinions are used to cover for these issues.

It must be noted that any study is as strong as its inputs allow it to be. Our risk assessment approach is qualitative by nature and its application depends on the soundness of expert inputs. To further objectify studies such as ours, it is recommended to include quantitative elements. Recent examples of these includes studies such as by Mohammad- 
fam and Zarei [50], as well as Zarei et al. [51] on hydrogen production plants, by Suzuki et al. [52] on hydrogen refuelling stations and by Nogutchi et al. [53] on hydrogen road transport in a city.

To finalize, it should be said that the most important aspect of the energy transition is the social value of hydrogen or green energy as a whole. The ultimate goal is to stop the planet from further deterioration, as stated by for instance the European Union. Concessions therefore should be made between suppliers, customers and transporters, as well as Dutch government bodies and European legislators, to develop a successful hydrogen economy.

Author Contributions: P.W.M.V., writing-original draft preparation; A.W.G.d.V., writing-review and editing; and W.W., writing-review and editing. All authors have read and agreed to the published version of the manuscript.

Funding: This research was funded by N.V. Nederlandse Gasunie.

Institutional Review Board Statement: Not applicable.

Informed Consent Statement: Not applicable.

Data Availability Statement: Specific data are drawn from publically available sources.

Conflicts of Interest: The funder had no role in the design of the study; in the collection, analyses, or interpretation of data; in the writing of the manuscript, or in the decision where to publish the results.

\section{References}

1. Acar, C.; Dincer, I. Review and evaluation of hydrogen production options for better environment. J. Clean. Prod. 2019, 218, 835-849. [CrossRef]

2. Kopteva, A.; Kalimulin, L.; Tcetkov, P. Prospects and obstacles for green hydrogen production in Russia. Energies 2021, 14, 718. [CrossRef]

3. Moradi, R.; Groth, K.M. Hydrogen storage and delivery: Review of the state-of-the-art technologies and risk and reliability analysis. Int. J. Hydrog. Energy 2019, 44, 12254-12269. [CrossRef]

4. Li, X.; Chen, G.; Chang, Y.; Xu, C. Risk-based operation safety analysis during maintenance activities of subsea pipelines. Process Saf. Environ. Prot. 2019, 122, 247-262. [CrossRef]

5. Mulder, M.; Perey, P.; Moraga, J.L. Outlook for a Dutch hydrogen market: Economic conditions and scenarios. CEER Policy Pap. 2019, 5, 1-82.

6. Trencher, G.; Edianto, A. Drivers and barriers to the adoption of fuel cell passenger vehicles and buses in Germany. Energies 2021, 14, 833. [CrossRef]

7. Cernat, A.; Pana, C.; Negurescu, N.; Lazaroiu, G.; Nutu, C.; Fuiorescu, D. Hydrogen-An alternative fuel for automotive diesel engines used in transportation. Sustainability 2020, 12, 9321. [CrossRef]

8. Almansoori, A.; Shah, N. Design and operation of a stochastic hydrogen supply chain network under demand uncertainty. Int. J. Hydrog. Energy 2012, 37, 3965-3977. [CrossRef]

9. Shishodia, A.; Dixit, V.; Verma, P. Project risk analysis based on project characteristics. Benchmarking Int. J. 2018, 25, 893-918. [CrossRef]

10. Koller, T.; Goedhart, M.; Wessels, D. Valuation: Measuring and Managing the Value of Companies; John Wiley \& Sons, Inc.: Hoboken, NJ, USA, 2020.

11. Ahmed, A.; Kayis, B.; Amornsawadwatana, S. A review of techniques for risk management in projects. Benchmarking Int. J. 2007, 14, 22-36. [CrossRef]

12. Malvestio, M. Developing a risk breakdown structure for a market entry: The Indian Case. PM World J. 2019, 8, 1-16.

13. Zou, Y.; Kiviniemi, A.; Jones, S.W.; Walsh, J. Risk information management for bridges by integrating risk breakdown structure into 3D/4D BIM. KSCE J. Civ. Eng. 2019, 23, 467-480. [CrossRef]

14. Elsye, V.; Latief, Y.; Sagita, L. Development of work breakdown structure (WBS) standard for producing the risk based structural work safety plan of building. MATEC Web Conf. 2018, 147, 1-12. [CrossRef]

15. Sigmund, Z.; Radujković, M. Risk breakdown structure for construction projects on existing buildings. Procedia Soc. Behav. Sci. 2014, 119, 894-901. [CrossRef]

16. Holzmann, V.; Spiegler, I. Developing risk breakdown structure for information technology organizations. Int. J. Proj. Manag. 2011, 29, 537-546. [CrossRef]

17. Larson, E.W.; Gray, C.F. Project Management: The Managerial Process; McGraw-Hill/Irwin: New York, NY, USA, 2011.

18. Zarutska, E.; Pavlov, R.; Pavlova, T.; Pawliszczy, D.; Kuchmacz, B. Main characteristics of business models and risk profile of Ukrainian banks. Financ. Credit Act. Probl. Theory Pract. 2020, 2, 15-22. [CrossRef] 
19. Connolly-Somich, S.D.; Daniels, M.R.; Moreno, G.P.; Kawig, R.; Lester, C.B.; Buchheit, A.; Sansbury, T.M.; Burnett, K.S.; Adams, I.I.M. Building a risk profile, USAFE-AFAFRICA Style. Armed Forces Comptrol. 2017, 63, 42-45.

20. Trestini, S.; Szathvary, S.; Pomarici, E.; Boatto, V. Assessing the risk profile of dairy farms: Application of the income stabilisation tool in Italy. Agric. Financ. Rev. 2018, 78, 195-208. [CrossRef]

21. Brayman, S.; Grable, J.E.; Griffin, P.; Finke, M. Assessing a client's risk profile: A review of solution providers. J. Financ. Serv. Prof. 2017, 71, 71-81.

22. Boritz, E.; Timoshenko, L.M. On the use of checklists in auditing: A commentary. Curr. Issues Audit. 2014, 8, C1-C25. [CrossRef]

23. Zhou, L.; Liu, W.; Ren, C.; Lü, K. Decision-making under uncertainty through extending influence diagrams with interval-valued parameters. Expert Syst. 2018, 35, 1-15. [CrossRef]

24. Abbasi, O.; Noorzai, E.; Gharouni Jafari, K.; Golabchi, M. Exploring the causes of delays in construction industry using a cause-and-effect diagram: Case study of Iran. J. Archit. Eng. 2020, 26, 05020008. [CrossRef]

25. Shenhar, A.J.; Dvir, D. Reinventing Project Management: The Diamond Approach to Successful Growth and Innovation; Harvard Business Review Press: Brighton, MA, USA, 2007.

26. Kendrick, T. Identifying and Managing Project Risk: Essential Tools for Failure-Proofing Your Project; AMACOM, American Management Association: New York, NY, USA, 2015.

27. Markert, F.; Marangon, A.; Carcassi, M.; Duijim, N.J. Risk and sustainability analysis of complex hydrogen infrastructures. Int. J. Hydrog. Energy 2017, 42, 7698-7706. [CrossRef]

28. Kikukawa, S.; Mitsuhasi, H.; Miyake, A. Risk assessment for liquid hydrogen fueling stations. Int. J. Hydrog. Energy 2009, 34, 1134-1141. [CrossRef]

29. Hansen, O.R. Hydrogen infrastructure-Efficient risk assessment and design optimization approach to ensure safe and practical solutions. Process Saf. Environ. Prot. 2020, 143, 164-176. [CrossRef]

30. Kasai, N.; Fujimoto, Y.; Yamashita, I.; Nagaoka, H. The qualitative risk assessment of an electrolytic hydrogen generation system. Int. J. Hydrog. Energy 2016, 41, 13308-13314. [CrossRef]

31. Kim, J.; Lee, Y.; Moon, I. An index-based risk assessment model for hydrogen infrastructure. Int. J. Hydrog. Energy 2011, 36, 6387-6398. [CrossRef]

32. Moonis, M.; Wilday, A.J.; Wardman, M.J. Semi-quantitative risk assessment of commercial scale supply chain of hydrogen fuel and implications for industry and society. Process Saf. Environ. Prot. 2010, 88, 97-108. [CrossRef]

33. Kim, J.; Moon, I. Strategic design of hydrogen infrastructure considering cost and safety using multiobjective optimization. Int. J. Hydrog. Energy 2008, 33, 5887-5896. [CrossRef]

34. Hefaidh, H.; Mébarek, D. A conceptual framework for risk matrix capitalization. Syst. Assur. Eng. Manag. 2020, 11, 755-764. [CrossRef]

35. Duan, Y.; Zhao, J.; Chen, J.; Bai, G. A Risk Matrix Analysis Method Based on Potential Risk Influence: A Case Study on Cryogenic Liquid Hydrogen Filling System. Process Saf. Environ. Prot. 2016, 102, 277-287. [CrossRef]

36. Hull, J.C. Risk Management and Financial Institutions; John Wiley \& Sons, Inc.: Hoboken, NJ, USA, 2018.

37. PwC Advisory. HyWay 27: Waterstoftransport via Het Bestaande Gasnetwerk? Eindrapport voor Het Ministerie van Economische Zaken en Klimaat. ("HyWay 27: Hydrogen Transport via the Existing Gas Network? Final Report for the Ministry of Economic Affairs and Climate"). 2021. Available online: https://www.hyway27.nl/ (accessed on 2 July 2021).

38. Siang, L.Y.; Ghazali, F.E.M.; Zainun, N.Y.; Ali, R. General risks for tunnelling projects: An overview. AIP Conf. Proc. 2017, 1892, $1-8$.

39. Gafari, M.A.; Aminzadeh, R. Identify and Analyze the Risks Involved in Tunnel Projects. Spec. Issue Curr. World Environ. 2015, 10, 1102-1108. [CrossRef]

40. Pompée, P.-J. Batisseurs Tunnel; Amicale Des Batisseurs Du Tunnel Sous La Manche: Calais, France, 2015; pp. 1-7.

41. Beard, A.N. Tunnel safety, risk assessment and decision-making. Tunn. Undergr. Space Technol. 2010, 25, 91-94. [CrossRef]

42. Anguera, R. The Channel Tunnel-An ex post economic valuation. Transp. Res. Part A 2006, 40, 291-315.

43. Colin, M.A.H.; Pilgrim, J.A. Cable thermal risk estimation for overplanted wind farms. IEEE Trans. Power Deliv. 2020, 35, 609-617. [CrossRef]

44. TenneT. Energy: From Sea to Land; TenneT TSO GmbH: Bayreuth, Germany, 2020.

45. TenneT. Connecting Wind Energy: The Offshore Grid in The Netherlands; TenneT TSO B.V.: Arnhem, The Netherlands, 2017.

46. Roetert, T.; Raaijmakers, T.; Borsje, B. Cable route optimization for offshore wind farms in morphodynamic areas. In Proceedings of the 27th International Ocean and Polar Engineering Conference, San Francisco, CA, USA, 25-30 June 2017.

47. Tam, V.W.Y.; Shen, L.Y. Risk management for contractors in marine projects. Organ. Technol. Manag. Constr. Int. J. 2012, 4, 403-410. [CrossRef]

48. Li, Y.; Kimura, S. Demand and Supply Potential of Hydrogen Energy in East Asia; ERIA Research Project Report 2018, No. 01; ERIA Economic Research Institute for Asean: Jakarta, Indonesia, 2019; pp. 1-202.

49. Hu, Y.; Liu, K.; Xu, D.; Zhai, Z.; Liu, H. Risk assessment of long-distance oil and gas pipeline based on grey clustering. In IEEE International Conference on Big Knowledge; IEEE: Piscataway, NJ, USA, 2017; pp. 198-201.

50. Mohammadfam, I.; Zarei, E. Safety risk modeling and major accidents analysis of hydrogen and natural gas releases: A comprehensive risk analysis framework. Int. J. Hydrog. Energy 2015, 40, 13653-13663. [CrossRef] 
51. Zarei, E.; Khan, F.; Yazdi, M. A dynamic risk model to analyze hydrogen infrastructure. Int. J. Hydrog. Energy 2021, $46,4626-4643$. [CrossRef]

52. Suzuki, T.; Shiota, K.; Izato, Y.; Komori, M.; Sato, K.; Takai, Y.; Ninomiya, T.; Miyake, A. Quantitative risk assessment using a Japanese hydrogen refueling station model. Int. J. Hydrog. Energy 2021, 46, 8329-8343. [CrossRef]

53. Noguchi, H.; Omachi, T.; Seya, H.; Fuse, M. A GIS-based risk assessment of hydrogen transport: Case study in Yokohama City. Int. J. Hydrog. Energy 2021, 46, 12420-12428. [CrossRef] 